\title{
The Development of a UK Kerbside Scheme Using Known Practice
}

\author{
R. Woodard, M. Bench \& M. K. Harder* \\ Waste \& Energy Research Group (WERG), School of the Environment, University of \\ Brighton, Lewes Road, Brighton, BN2 4GJ, UK \\ * Corresponding author. Tel: + 44-1273-642539; fax + 44-1273-642285 \\ E-mail address: m.k.harder@brighton.ac.uk (M.K. Harder)
}

\begin{abstract}
Local authorities in the UK have been set challenging new targets for recycling household waste for 2005. This means many of them are urgently trying to determine which parameters in kerbside schemes are most important for increasing recycling rates. In this work information from previous kerbside schemes is used to plan significant improvements in an existing scheme in Horsham District, UK, and trialled using 1,000 homes including a control group. It used fortnightly collection of residual waste with sets of recyclables collected on alternate weeks. The new scheme resulted in improvements of participation rates from $72 \%$ to $84 \%$, and set-out rates of $45 \%$ to $59 \%$ (falling to $76 \%$ and $50 \%$ respectively some months later). Details on participation and set-out for different groups of materials is given, as well as levels of excess waste and participation in the collection of garden waste.
\end{abstract}

Key words: Household waste; Kerbside recycling; Education; Waste collection

\section{Introduction}

In $2001 / 02,77 \%$ of the 28.8 million tonnes of municipal waste generated in the UK was sent to landfill for disposal (DEFRA, 2003). However landfill void space in the UK is running out to the extent that the Environment Agency have estimated that existing capacity in the south-east of England will be exhausted within seven years (Environment Agency, 2000). Moreover, landfill disposal has many environmental and social burdens. Odour, aesthetic degradation, vermin, traffic congestion, health implications, and air and water pollution are all issues associated with landfill sites (European Environment Agency, 1999; Redfearn et al. 2000).

These pressures have led to UK and European attempts to legislate for a reduction in the reliance on landfill disposal, whilst promoting other options. An early indication of this was in 'This Common Inheritance', the UK government's first comprehensive White Paper on the Environment in 1990. This document set out a waste strategy that regarded waste minimisation and recycling as priorities and set a $25 \%$ recycling target for household waste by 2000 (Great Britain, 1990a). This policy document led to the publication of the government's White Paper on waste management in 1995, 'Making Waste Work'. It set out the national waste management strategy for England and Wales, and confirmed the $25 \%$ household waste recycling target by 2000 (DoE, 1995). 
However, the UK failed to achieve the $25 \%$ recycling target by this date, only attaining a rate of $9 \%$. In the same year the government published Waste Strategy 2000, which is seen as the current waste strategy for England and Wales and sets out how household waste will be managed until 2020. It postponed the $25 \%$ recycling target date until 2005, and set subsequent recycling and recovery targets (DETR, 2000). Waste Strategy 2000 was a pivotal document as it set out how these recycling targets would be met, with, for the first time, each local authority in England being set individual statutory recycling targets based upon previous recycling performance (DETR, 2001). For example, authorities with a recycling or composting rate of under $5 \%$ in 2000 had to achieve $10 \%$ by 2005 . Those attaining between $5 \%$ and $15 \%$ had to double their rate, and the remaining authorities - the highest achievers - had to recycle or compost at least one third of household waste by 2003/04 (DETR, 2000). The penalty of failing to meet these targets may include fines or forfeit of duties (DETR, 2001). The extent of the execution of these penalties remains to be seen.

Local authorities throughout the UK are therefore revising their waste management structure and recycling strategies as they attempt to achieve their respective targets. An important part of this process is the provision of kerbside recycling - the collection of materials directly from the household. The introduction of a kerbside recycling collection scheme has been identified as a primary motivator in encouraging previous non-recyclers to recycle (Coggins, 1994; Miller Associates, 1999). Jenkins et al., (2003) suggest that a kerbside programme reduces a household's cost of recycling by making recycling convenient and less time consuming.

If local authorities are to increase their respective recycling rates then existing schemes will need to be adapted and new collection schemes implemented. But what changes can be made to these existing schemes so that participation and material capture rates increase? The work reported here considers this question, which at present is of importance to all local authorities in the UK. The parameters that appear to contribute towards the performance of a successful kerbside scheme are summarised from literature available in 2002/03, and a pilot scheme was devised, carried out and evaluated for Horsham District the UK.

\section{Background - Recycling in the UK}

It was not until the 1980s that kerbside-recycling schemes began to be established in the UK and by 1993, 40 different schemes were in operation (Coggins, 1994). As local authorities attempt to meet their statutory targets, more kerbside recycling schemes are becoming established, with some $58 \%$ of households now being offered a kerbside recycling service (see Figure 1). The quantities collected through kerbside recycling have in turn increased dramatically. In 1996/97 329,000 tonnes of recyclable materials were set out in kerbside collections, but by 2001/02 this had increased to 962,000 tonnes. The contribution of kerbside schemes to the overall household waste recycling rate has increased from 23\% in 1996/97 to $31 \%$ in 2001/02. There is great variation in the level of scheme offered; although $24 \%$ of households are provided with a scheme that collects four or more materials, $12 \%$ are only offered a collection service for one, usually paper (DEFRA, 2003). 
Many authorities are in the process of expanding their kerbside recycling provision; the one used for the trial in this work is typical - Horsham District Council.

Figure 1. Coverage of kerbside recycling in the UK (DEFRA,

2003)

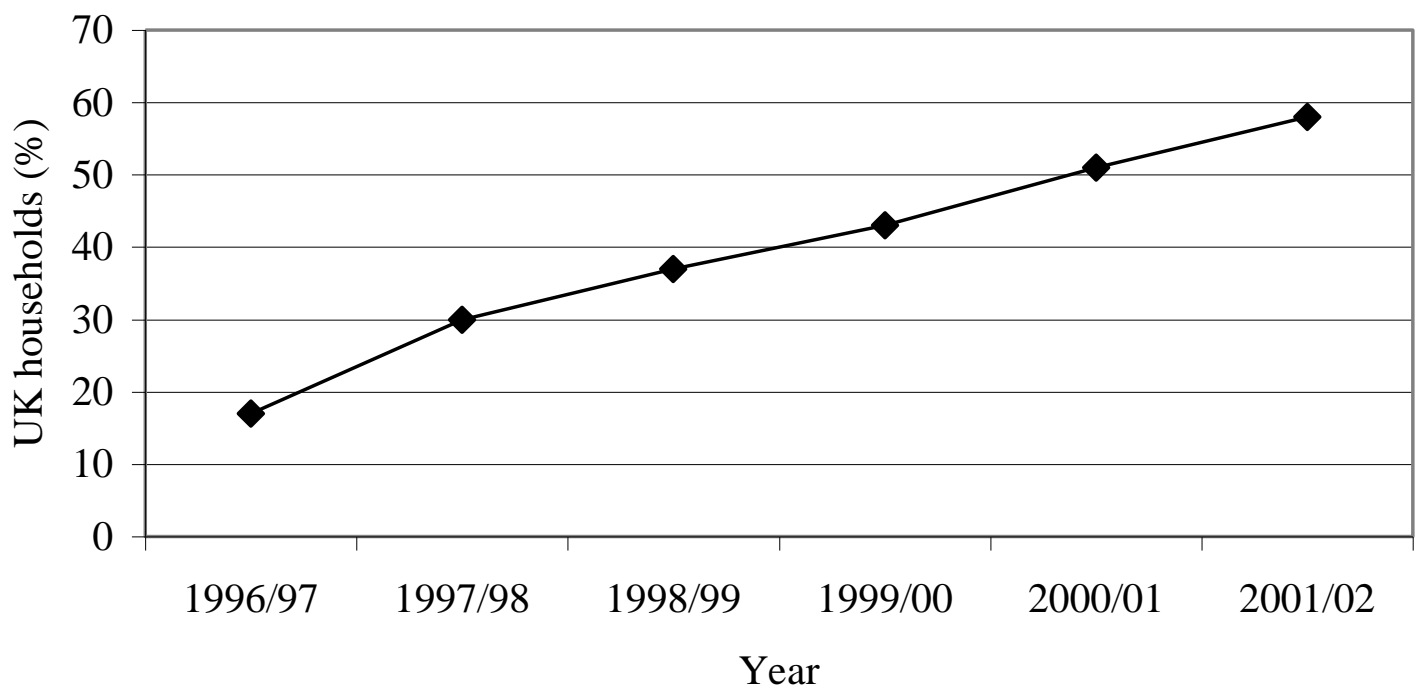

\section{Horsham District Information}

\subsection{Profile}

Horsham District is located in the county of West Sussex in the south east of England. Covering some 205 square miles, it is one of seven districts in West Sussex and is home to some 123,000 residents. Horsham is a district with a highly qualified and affluent population (see Table 1).

Table 1. Profile of Horsham District (National Statistics, 2003)

\begin{tabular}{|c|c|c|c|}
\hline Number of people & No. & $\begin{array}{l}\text { Ranking in England } \\
\text { and Wales out of } 376 \\
\text { authorities (1 is } \\
\text { highest) }\end{array}$ & $\begin{array}{l}\text { Ranking in the south } \\
\text { east region out of } 67 \\
\text { authorities (1 is } \\
\text { highest) }\end{array}$ \\
\hline Per hectare & 2.3 & 256 & 53 \\
\hline Per household (average) & 2.38 & 154 & 38 \\
\hline Employed & 59,365 & 40 & 21 \\
\hline Unemployed & 1,363 & 371 & 63 \\
\hline Retired & 12,235 & 199 & 25 \\
\hline $\begin{array}{l}\text { Qualified to degree level } \\
\text { or above }\end{array}$ & 20,224 & 77 & 23 \\
\hline $\begin{array}{l}\text { With limiting long term } \\
\text { health }\end{array}$ & 16,459 & 347 & 49 \\
\hline $\begin{array}{l}\text { Travelling to work by car } \\
\text { Number of households }\end{array}$ & 41,836 & 135 & 18 \\
\hline
\end{tabular}




\begin{tabular}{llll} 
With residents & 50,057 & 166 & 27 \\
Owner occupied & 39,552 & 44 & 14 \\
No car & 6,229 & 366 & 61 \\
Two cars or more & 23,871 & 11 & 8 \\
\hline
\end{tabular}

\subsection{Horsham's Kerbside Scheme in 2000 - the starting point}

Despite the majority of Horsham District being provided with comprehensive kerbside scheme, it was only achieving a $13 \%$ recycling rate in 2000 , needing to be increased to $26 \%$ by $2003 / 4$. Investigations were therefore carried out to assess what specific, efficient changes could be made to the existing service to increase the recycling rate. Whilst many studies have been published reporting on the results of individual collection schemes few offer a review of the components that appear to influence their performance.

In the existing waste collection system, the majority of households had their (residual) waste collected each week using 140 litre wheeled bins, though some residents supplied their own containers. A kerbside service was offered to most households with newspapers and magazines collected one week, plastic bottles and cans the following week. This kerbside service, combined with recycling centres (bring banks) led to the district achieving a 13\% recycling rate in 1998/99 (DETR, 2001).

Further to Waste Strategy 2000 and the subsequent introduction of statutory recycling targets, Horsham was set the challenge of doubling their recycling rate to $26 \%$ by $2003 / 04$ and $36 \%$ by $2005 / 06$. This paper reports on the revised scheme devised to increase the recycling rate, and how the new scheme took into account relevant parameters from previous studies (i.e. up to 2002/03).

\section{Assessment of Kerbside Scheme Parameters from Published Work}

A variety of parameters used in reported kerbside recycling schemes are discussed in turn, and their feasibility for inclusion in the revised Horsham scheme is assessed.

\subsection{Provision of collection container}

Noehammer et al. (1997) suggest that local authorities have three options with respect to providing a collection container; providing a container to residents free of charge, charging residents for a specific container or providing no container. Research shows that kerbside recycling programmes that supply a container capture more materials than those that do not (Everett et al. 1993) and that the participation rate is higher (Platt et al. 1991). Reasons for this maybe increased convenience, a visual reminder to recycle and additional peer pressure since the absence of a recycling container placed out for collection clearly identifies a non-recycler.

The collection and sorting infrastructure will have an influence upon the type and number of containers used. Some authorities have compartmentalised vehicles, which allow for co-mingled collection of recyclable materials that can then be sorted at the kerbside. Other authorities operate Materials Recovery Facilities (MRF) where co- 
mingled recyclable materials can be sorted at a central point. Where this system is in place authorities sometimes collect materials using one container, such as a wheeled bin or a survival sack (a transparent plastic bag). Some 3 million households have their recyclable materials using a co-mingled system (DEFRA, 2003). In the existing scheme residents used baskets for recyclable materials and wheeled bins for residual waste.

A variety of containers are used in recycling collections and were reported on. These vary in size and design but the most popular is a plastic box with a lid. An alternative is the use of a reusable bag. Residents are supplied with woven sacks, which are placed out for collection and then returned to the households (Woodard et al. 2002). The problems associated with sacks include a limited lifetime, dampness and handling (WERG, 2001).

Plastic bags are sometimes used with tags; householders place materials in a bag (such as a supermarket shopping bag), tie a tag or a label on it identifying it as recyclable material, and place it out for collection (Read, 1999). Whilst this approach is cheap, there are issues with residents clearly marking the bags, so they are often taken as part of the refuse collection (WERG, 2002). Furthermore, research has illustrated that the public will participate more if they are supplied with a designated container (Everett et al. 1993).

Though $52 \%$ of authorities in England and Wales use wheeled bins to collect waste (DEFRA, 2003) these containers are also used to collect recyclable materials. An advantage of wheeled bins is that they do not need lifting by residents and as they are available in a variety of sizes, they can be tailored to meet the requirements of individual households. However, wheeled bins are more expensive that other methods and are not suitable for all neighbourhoods such as stepped areas or dense housing where storage is an issue.

Although it was understood from the research mentioned above that an unsuitable container could make a significant difference to participation in a recycling scheme, there did not seem to be any problems with the containers already in use on the existing Horsham scheme. These were 140 litre wheeled bins and 36 litre baskets. For the revised scheme it was decided to continue to use these, but to supply additional or alternative containers to those who indicated a need.

Emphasis was placed upon making the system as manageable and user friendly as possible. All households were given the option of having an extra 240 litre wheeled bin. A flexible approach was taken so that either it or the new 140 litre bin could be used for residual waste, but only the contents of one would be emptied. Households could also request extra baskets for dry recyclable materials and they could place out as many bins or baskets for recyclable materials as necessary for collection.

\subsection{Collection frequency}

The most common frequency for the collection of recyclable materials in England and Wales is fortnightly (DEFRA, 2003). The two main reasons for this are that authorities cannot afford to operate a weekly service and that the yields of material do not justify a more frequent collection. Research by Platt et al. (1991) has shown that 
frequency of recycling collection can have a big influence upon participation and material recovered. Everett et al. (1993) suggest that weekly collection of recyclable materials captures more newspapers and glass than other collection frequencies but less aluminium.

The majority of UK residents are used to having their waste collected each week. This issue perhaps needs addressing if the UK is to increase its recycling rate. The public's perception to waste collection is that it is a system dominated by the collection of waste with an additional recycling service. This needs changing so that the public perceive collection of the recyclable fraction as being the main element of the system. Some authorities are attempting to achieve this by reducing the frequency of refuse collection whilst at the same time increasing the range of the recyclable materials that they collect. For example, Wealden District Council changed its collection of residual waste to every second week, but collected recyclable garden waste on the other weeks. They continued to collect other (dry) recyclables every two weeks, and in the parts of the district where the scheme was in operation an average recycling rate of 48\% was recorded (The Environment Council, 2000).

The alternate collection approach is becoming increasingly popular throughout the UK with Exeter, St Edmunsdbury, Torbay and Teignbridge Council using such a system. The two authorities recording the highest recycling rate in the UK, Daventry (42\%), and Eastleigh (32\%) use a similar scheme. Interestingly, Daventry, which has the highest rate, collects recyclables weekly and garden waste and residual waste on alternate weeks whilst in Eastleigh dry recyclables and residual waste are collected on alternate weeks (DEFRA, 2002a).

Some authorities have faced problems convincing their residents that alternate collection of residual waste is a valid approach, with objections based on public health issues, as in the London borough of Sutton (Kendall, 2001). Despite these concerns, it has been shown that the alternate weekly collection of residual waste and recyclable materials can work well, and it was therefore integrated into the new Horsham scheme.

\subsection{Materials collected}

A review of kerbside schemes in the England and Wales shows that $12 \%$ of all households are offered a scheme that collects just one material whereas $24 \%$ of households have four or more materials collected (DEFRA, 2003). Cardboard and paper is the most commonly collected material with $47 \%$ of all households offered a service. Cans, glass, organic material and textiles are also collected frequently with some $15 \%$ or more of all households provided with a service for these materials (DEFRA, 2003).

In 2001, waste composition analysis was conducted in Horsham (see Figure 2). From the analysis it was possible to calculate capture rates for the materials (newspapers, magazines, plastic bottles and cans) collected in the existing scheme (see Figure 3). Each of the prominent materials remaining in the waste stream was assessed for their suitability for inclusion in the new scheme. 
Figure 2. Composition of household waste in Horsham (adapted from Network Recycling, 2001)

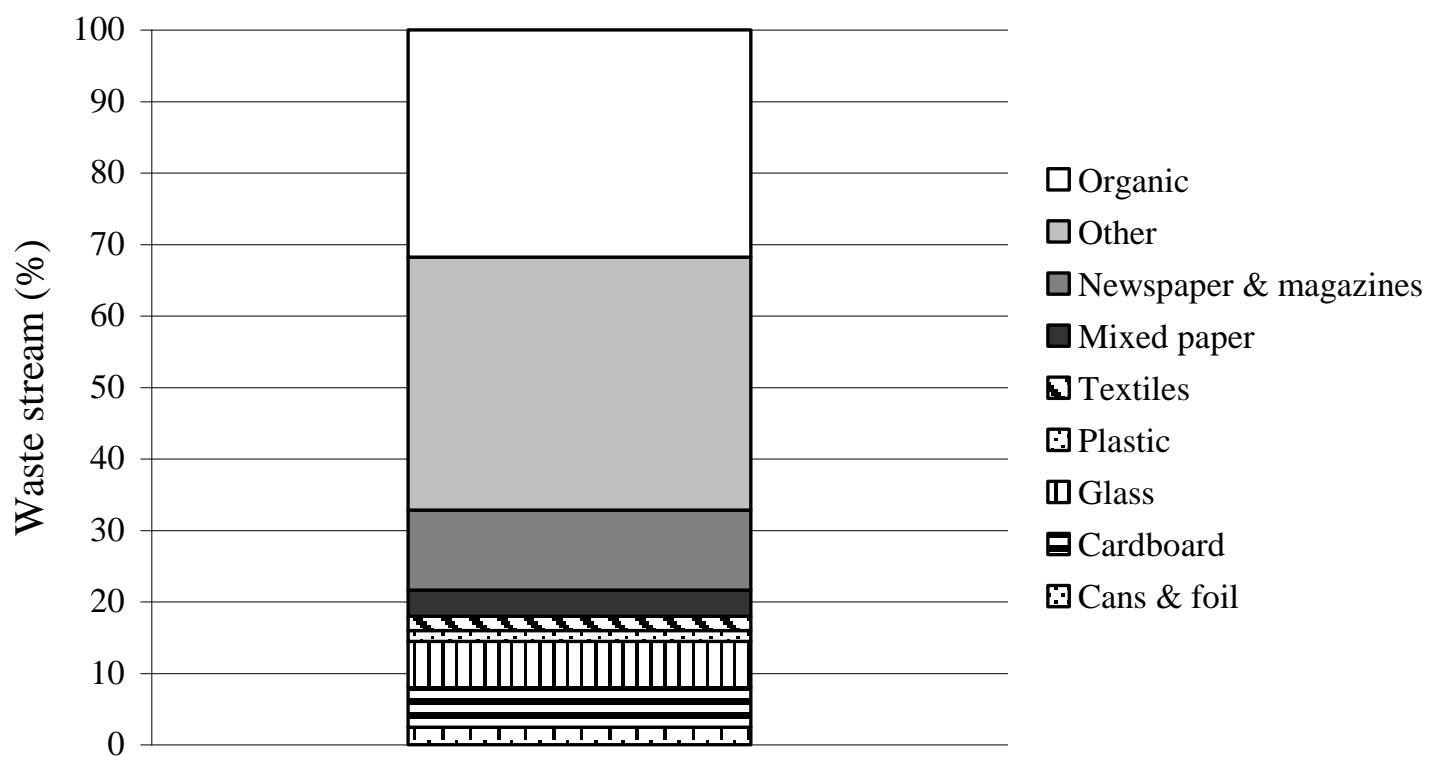

\subsubsection{Existing recyclables}

Fourteen percent of the waste stream consisted of materials that could be recycled in the existing scheme. Analysis showed that 53\% of newspapers and magazines were being captured for recycling whilst $45 \%$ of HDPE and PET bottles were being

Figure 3. Material capture rates in Horsham (Adapted from Network Recycling 2001)

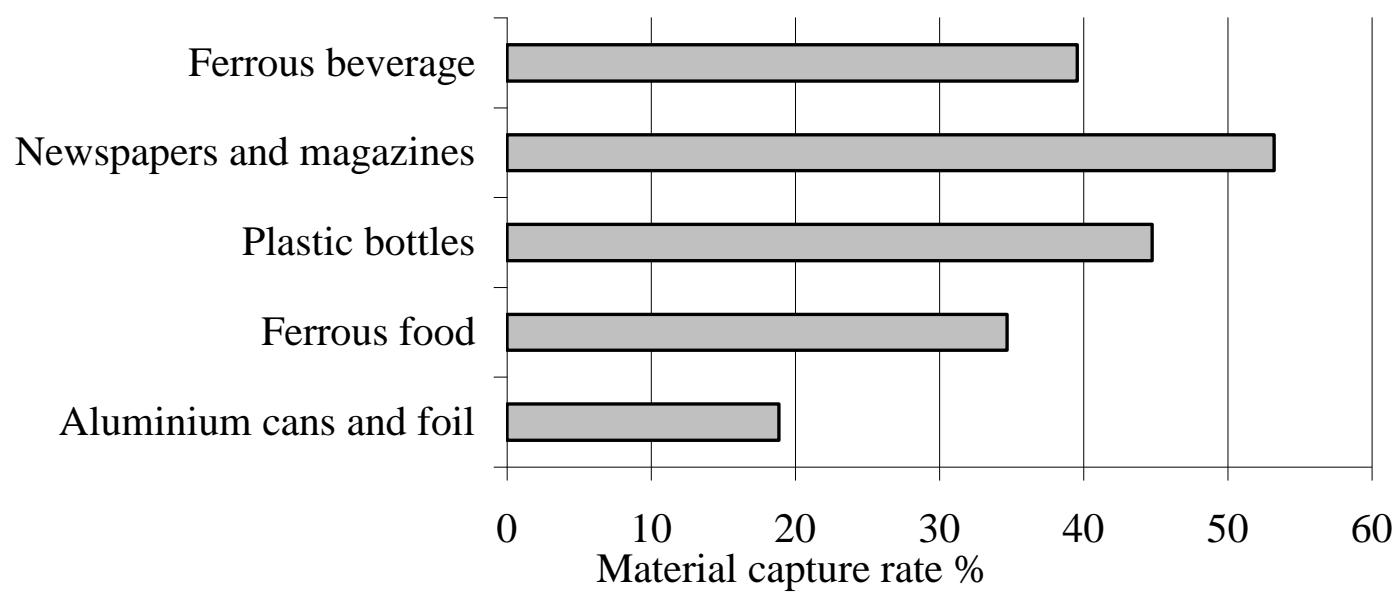

diverted (see Figure 3). Capture was lower for metal packaging, with $45 \%$ of ferrous beverage cans and 35\% of ferrous food containers being placed out for collection. The lowest rate was recorded for aluminium cans and foil, with only $19 \%$ being captured. 
The first objective of the new scheme would be to increase the capture rate of these materials.

\subsubsection{Organics}

The collection of organic waste in kerbside collection schemes is becoming increasingly popular (Waste Watch, 1999; Woodard et al. 2001; Williams \& Kelly, 2003). Organic material is a principle component of household waste and is therefore a desirable fraction to collect. In Horsham $32 \%$ of the organic wastes sampled were classified as organic, and this material could be collected and used to manufacture compost (see Figure 2). However, the collection of all organic material was not viable. Elements such as cooked food, meat, dairy products and bones are not desirable to include in compost. In 2001 there was an outbreak of Foot and Mouth disease in the UK which resulted in some 4 million sheep, cattle and pigs being slaughtered to prevent the spread of the disease. The overall costs of the outbreak were enormous totalling over $£ 8$ billion. The suspected cause of the outbreak was the feeding of unprocessed food waste to animals (DEFRA, 2002b). At the time of study, the climate regarding handling of food wastes meant that it would not have been prudent to incorporate these materials into the collection until the release of further guidance.

The remaining material, 'green' garden waste such as trimmings, cuttings and leaves was suitable for inclusion in a collection scheme. Garden waste was reported at $3 \%$ of household waste arisings, which when compared to some other waste analyses seemed very low (Parfitt, 2002). This might be due to the analysis being conducted in March, a time of low garden waste production, or that a large proportion of garden waste is delivered to centralised facilities for bulky wastes known as civic amenity sites (Bench et al. 2003). It was decided to trust figures reported elsewhere, and include garden waste for recycling in the revised Horsham scheme.

\subsubsection{Mixed paper}

Some 540,000 tonnes of paper and cardboard were collected for recycling through kerbside schemes in 2001/02 (DEFRA, 2003). Whilst the existing scheme in Horsham collected newspapers and magazines, mixed paper was not included. Analysis suggests that mixed papers comprised $4 \%$ of the household waste stream (see Figure 2 ). If the collection of mixed paper was introduced two approaches could be implemented: collection of all paper together or two separate collections of mixed paper and newspaper with magazines.

The price paid for newspapers and magazines is considerably higher than that paid for mixed paper. Authorities can expect to receive $£ 45-53$ per tonne for newspapers and magazines but only £23-35 per tonne for mixed paper (Letsrecycle.com, 2003). Paper mills are also demanding source segregated material with a better quality of paper in the secondary market (PaperChain, 2002). Horsham District Council indicated it would prefer not to change to mixed paper collection at this time, although the potential increase in recycling rates was noted for future reference.

\subsubsection{Cardboard}


Six percent of the total sampled waste stream was cardboard (see Figure 2). There are two main types of this material; corrugated cardboard, used in the manufacture of cardboard boxes represented $2 \%$ and packaging cardboard, as used in cereal boxes the remaining $4 \%$. Cardboard can be integrated as part of a garden waste collection (packaging cardboard only), in a segregated cardboard collection or included in a mixed paper collection. As the collection of garden waste had previously been identified inclusion of packaging cardboard in this segregation appeared the most viable option.

\subsubsection{Textiles}

Two percent of the sampled waste stream was textiles (see Figure 2). This included bedding, shoes and clothing. Daneshvary et al. (1998) conducted research into textile recycling habits of residents in Nevada, USA and found that $81 \%$ of respondents donated textiles to charitable organisations. Similarly, in the UK textile recycling revolves heavily around charities. A successful nationwide collection system is in place supported by the Salvation Army. Their factory in Kettering handles 1.5 million items of clothing each week (Salvation Army, 2002). Therefore, it was preferable for the council to support this service rather than implementing their own.

\subsubsection{Glass}

Glass has not traditionally been included in kerbside schemes due to problems of handling and the necessity for colour separation. However, recent research suggests that the perception of handling issues are largely unfounded and the development of glass into an aggregate has made kerbside collections more feasible (WRAP, 2002). Moreover, some 64,000 tonnes of glass was collected through kerbside schemes in 2001/02 (DEFRA, 2003).

Approximately $6 \%$ of the sampled household waste stream was glass (see Figure 2). The Council decided to implement a separate collection trial for glass and therefore the material was not integrated into the system described.

In summary, analysis of the waste stream identified that the most desirable materials for inclusion in the new collection scheme were the existing dry recyclables; cans, plastics bottles, newspapers and magazines with the addition of packaging cardboard and garden waste. These materials represented $22 \%$ of the existing residual stream, though it was expected that levels of garden waste were higher than those reported. The possibility that collecting mixed paper instead of newspaper \& magazines could increase recycling rates further was noted for future reference.

It was thus decided that the new scheme proposed would include alternate collections of residual and recyclable garden waste in large bins, with dry recyclates collected in boxes every fortnight. Unlike the existing scheme, no excess residual waste (waste outside the wheeled bin) would be accepted for collection. Residents would therefore have to make use of the garden waste recycling service and the dry recyclates collection service as well as the local recycling centres (bring banks) in order to effectively manage their waste. The scheme attempted to formulate a 'waste week' and 'recycling week' mentality in the residents 


\subsection{Collection day}

Recyclable materials can either be collected on the same or different days as the residual fraction. Factors that influence the day of collection include the cost to the council and the convenience to the householders. Folz et al. (1991), Everett et al. (1993) and Noehammer et al. (1997) found no relationship between the day of collection and participation. It was thus decided that this was not a parameter significant enough to have a bearing on the new Horsham scheme.

\subsection{Collection vehicle}

There are several vehicle types available to local authorities for collecting recyclable material. These include refuse collection vehicles, split bodied, compartmentalised and caged vehicles. Factors that influence the vehicle used include economic, logistics of the collection area and the local sorting infrastructure.

It was decided that the collection vehicle type was not critical to this trial. However in the long term it was agreed that the vehicles accepting recycled materials should be visually different to those collecting residual waste, so that the public could clearly distinguish between the two collections.

\subsection{Education}

Recycling, and other forms of waste management, need to be adequately communicated to the public, so that residents' habits, behaviour and traditions can change for the better, to enable local authorities to achieve government goals of recycling and recovery (Read, 1999). However it is interesting to note that some research suggests that there is no link between the right attitude and participation in recycling schemes. No matter if people recycle or not they believe that recycling is the right thing to do and is extremely important to the preservation of the environment (De Young, 1990; Wang et al. 1997).

Read (1999) reviewed common forms of communication used by UK local authorities and classified methods as being passive, active or interactive (see Table 2).

Passive forms include leaflets, reminder cards and public events. The active approach incorporates promotional videos and provision of containers. Whilst passive and active approaches towards communication are both traditional, the interactive approach is a new idea that includes door to door surveys and public visits to facilities. This style of communication is becoming increasingly popular as local authorities attempt to raise waste awareness.

Table 2. Common methods of UK local government communication promoting waste management (Read, 1999)

\begin{tabular}{lll}
\hline Passive approach & Active approach & Interactive approach \\
\hline $\begin{array}{l}\text { Advertising on collection } \\
\text { vehicles }\end{array}$ & $\begin{array}{l}\text { Cards delivered door-to- } \\
\text { door to explain the system }\end{array}$ & $\begin{array}{l}\text { Door-to-door surveys and } \\
\text { education }\end{array}$ \\
$\begin{array}{l}\text { Displays for use at fairs } \\
\text { and public events }\end{array}$ & $\begin{array}{l}\text { Collection receptacles } \\
\text { provided free to residents }\end{array}$ & $\begin{array}{l}\text { Presentations in schools, to } \\
\text { groups or at conferences }\end{array}$
\end{tabular}


Household leaflets

Newspaper articles each

month covering waste

Reminder cards, answering questions

Sticker to designate Display boards
Promotional videos

Seasonal promotion encourage participation

Community newsletters
Public meetings

to Radio spots, adverts or phone-ins

Telephone hotline

Visits to the recycling centre/education facility

The education campaign in the Royal Borough of Kensington and Chelsea, London, is a good example of an interactive approach. Despite offering an extensive kerbside recycling service, the borough was only achieving an $11 \%$ recycling rate. The Council wanted to increase levels of waste awareness in the borough which in turn would hopefully result in a higher recycling rate. Each household in the borough was visited as part of a project in partnership with the University of Kingston. Residents were informed of the kerbside service and attempts were made to persuade non-recyclers to use the service. The project yielded some interesting results; following the project, the average weekly tonnage of recyclables collected increased by $19 \%$. Moreover, $31 \%$ of households questioned had not ever heard of the kerbside service. Therefore it appears the interactive approach can have a marked impact on increasing levels of waste awareness and can provide useful data on which to base a waste awareness strategy (Read, 1999).

It was decided that education should be an important component of the new Horsham scheme and emphasis was placed upon interactive communication with residents. An information pack was developed and supplied in a reusable cloth bag. It included a calendar for the dates of collection, a list of materials that could be included in the scheme, recycling and waste stickers for the bins, information on why the scheme was being introduced and details of local recycling facilities. The packs, along with the containers, were delivered by Magpie Solutions, a community group who have over 10 years of recycling experience in Brighton \& Hove City. Operatives called at each household on the trial, presented them with the container and packs and allowed the residents to ask questions about the scheme. This is very different to the common practice of leaving containers on the doorstep with a leaflet, and the new approach aimed to really engage residents and give them provide them with an opportunity to learn more about recycling.

However, as some residents may not be at home, it would not be possible to engage all of them using this approach. Road shows, where the purpose and dynamics of the scheme are presented, were also organised that enabled residents to question council officers directly.

\subsection{Incentives}

It is a common belief that economic incentives increase participation in recycling programmes (Andress, 1990; Platt et al. 1991; Harder et al. 1992). Research suggests that $95 \%$ of recycling officers feel that money incentives are required to make recycling succeed (Herridge, 2001). Noehammer et al. (1997) identified two forms of economic incentives; user fees systems and fine-and-reward systems. 
In user fee systems (also referred to as variable charging), residents are charged a fee based upon the quantity of waste that they generate. This approach is well established in many other industrialised countries and in some parts of the USA have in place for over 80 years (Strategy Unit, 2002). As residents have to pay in relation to how much waste they generate it is hoped that they will make full use of the recycling facilities on offer. In the UK residents have traditionally paid for waste management services through taxation and the Environmental Protection Act of 1990 prohibits authorities from charging households directly (Great Britain, 1990b).

An alternative is fine-and-reward systems where residents are penalised or rewarded based upon their recycling actions. Residents that fail to sort their recyclable materials correctly maybe fined whilst those residents that participate in a scheme and segregate their waste into the correct containers maybe given a reward. In recent years reward schemes have began to be trialled in the UK with examples in Brent and Lambeth where residents were given a $£ 10$ incentive if they recycled at least half of the time over a 6 month period (Strategy Unit, 2002).

At the time of study local authorities were prohibited from implementing user fee schemes and could not fine residents for failing to partake in recycling. However, they could reward households for taking part and it was decided that some form of incentive should be integrated into the revised scheme. To reward residents for taking part they were given a free bag of compost manufactured by the company accepting the garden waste generated in the trial.

The new scheme was designed and tested in part of Horsham. The methodology used in monitoring and evaluating the system is presented in the following section.

\section{Monitoring and Evaluation Methodology}

\subsection{Selection of appropriate rounds}

A collection round containing 1,000 households was required for the trials. Details of each collection round in the district were assessed so that a round could be selected that had the closest socio-demographic profile to Horsham District as a whole. Research suggests that within different demographic groups environmental behaviour varies (Pocock 1989; Belton et al. 1994). ACORN (A Classification Of Residential Neighbourhoods) profiling is used to categorise demographic groups. Households that have similar consumer habits are classified into one of six broad groups which in turn contain 54 sub groups (CACI, 2002). It is assumed that households of the same ACORN category produce waste in similar quantities and composition. ACORN profiling was used most extensively in the National Household Waste Analysis Programme (DoE, 1994). The round selected therefore had the closest ACORN profile to that of the district.

Five hundred households were integrated onto the new system (hereafter referred to as the trial group) with the remaining households kept on the existing scheme (hereafter referred to as the control group). The inclusion of the control group would allow good comparisons to be made about how the trials may influence recycling habits.

\subsection{Monitoring}


Three key stages of monitoring were conducted; four weeks pre-commencement, four weeks immediately after commencement, and four weeks monitoring several months later.

\subsubsection{Phase 1: Pre-trial monitoring}

All households were monitored for a four-week period prior to any announcement in regards to the new scheme. There were several reasons for this Phase; to gain an understanding of the area, to measure set out rates, participation rates and gauge levels of excess waste and to remove non-suitable households from the trial. The findings from Phase 1 would provide base-line information about participation on the existing scheme. As data was collected on a household basis this Phase would also allow for a direct comparison of individual household recycling habits once the trials had been implemented. As part of the study, two established sampling tools were used to gauge recycling activity (see Table 3 ).

The set out ratio is used to calculate the number of households placing out their recyclable materials on any given day (DETR, 1999). Participation ratio is used to calculate how many households actively take part in recycling over a four-week period (DETR, 1999). Some households may not place recyclable materials out in each collection as they may not generate enough or they may forget. However, it is likely that if they actively recycle they will place materials out at least once in a fourweek period.

Table 3. Formulae for sampling tools (DETR, 1999)

\begin{tabular}{|c|c|}
\hline Set out ratio $=$ & $\frac{\text { No of households placing material out for collection }}{\text { Total no of households }} \times 100$ \\
\hline Participation ratio $=$ & $\begin{array}{l}\text { No of households placing materials out for collection } \times 100 \\
\frac{\text { At least once in a four week period }}{\text { Total no of households }}\end{array}$ \\
\hline
\end{tabular}

\subsubsection{Phase 2 \& 3: Households monitored immediately and months later}

Immediately following the commencement of the scheme, all households were monitored for a four week period, where highest rates of participation can be expected. As in Phase 1 levels of set out, participation and excess waste data were recorded.

Households were then monitored for a further four weeks, several months after the commencement of the trials. Previous research has indicated that participation in recycling schemes drops off after the initial period of a scheme being introduced (Woodard et al. 2002), and this monitoring allowed that trend to be studied.

\subsection{Weighing}


Throughout the trials, weights of collected materials were recorded from both control and trial areas. This allowed the recycling rate to be calculated. Some weighing of individual recycling baskets was also carried out at the kerbside using spring balances and observations were made of how full the containers were.

\section{Key Recycling Results from the New Scheme}

The key results of the new scheme are presented in this section according to three Phases of analysis; pre-trial (Phase 1), initial analysis immediately after the implementation of the trials (Phase 2) and further analysis several months later (Phase 3 ). The results from Phases 1, 2 and 3 of analysis are shown in Table 4, the frequency at which households participated in Table 5, levels of excess waste in Table 6 and the results for garden waste recycling are presented in Table 7.

Table 4. Results of monitoring

\begin{tabular}{lllll}
\hline & Week & Material collected & Trial area (\%) & Control area (\%) \\
\hline Phase 1 & 1 & C\&P & 49 & 43 \\
& 2 & Pa & 39 & 31 \\
& 3 & C\&P & 53 & 43 \\
& 4 & Pa & 39 & 37 \\
& SR & $\varnothing$ & 45 & 39 \\
& PR & $\Sigma$ & 72 & 64 \\
Phase 2 & 1 & Pa & 53 & 37 \\
& 2 & C\&P & 65 & 43 \\
& 3 & Pa & 55 & 39 \\
& 4 & C\&P & 62 & 46 \\
& SR & $\varnothing$ & 59 & 41 \\
& PR & $\Sigma$ & 84 & 64 \\
& 1 & Pa & 51 & 39 \\
& 2 & C\&P & 55 & 41 \\
& 3 & Pa & 42 & 34 \\
& 4 & C\&P & 50 & 44 \\
& SR & $\varnothing$ & 50 & 64 \\
& PR & $\Sigma$ & 76 &
\end{tabular}

Table 5. Level of participation in recycling

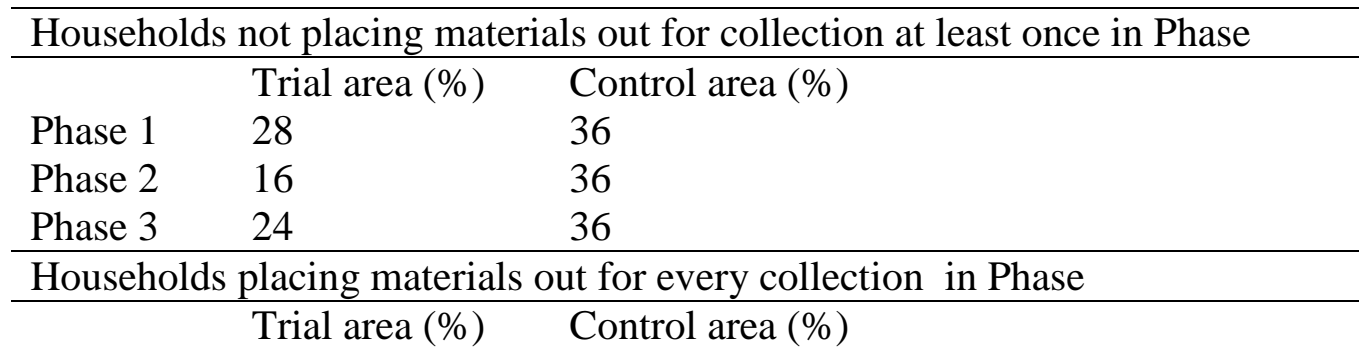


Phase $1 \quad 14 \quad 11$

Phase $2 \quad 27 \quad 16$

Phase $3 \quad 20 \quad 15$

Table 6. Levels of excess waste placed out for collection

\begin{tabular}{|c|c|c|c|}
\hline & Week & Trial area $(\%)$ & Control area $(\%)$ \\
\hline \multirow[t]{3}{*}{ Phase 1} & 2 & 15 & 7 \\
\hline & 4 & 8 & 7 \\
\hline & $\varnothing$ & 12 & 7 \\
\hline \multirow[t]{3}{*}{ Phase 2} & 2 & 0 & 10 \\
\hline & 4 & 4 & 11 \\
\hline & $\varnothing$ & 2 & 11 \\
\hline \multirow[t]{3}{*}{ Phase 3} & 2 & 1 & 9 \\
\hline & 4 & 8 & 7 \\
\hline & $\varnothing$ & 5 & 8 \\
\hline
\end{tabular}

Table 7. Participation in garden waste recycling only - all Phases

\begin{tabular}{lllll}
\hline & Week & Trial & $\begin{array}{l}\text { PR for dry recyclable } \\
\text { materials only }\end{array}$ & $\begin{array}{l}\text { PR for all materials } \\
\text { including garden waste }\end{array}$ \\
\hline Phase 2 & 1 & 74 & & \\
& 3 & 73 & & 92 \\
& PR & 86 & 84 & \\
Phase 3 & 1 & 59 & & 84 \\
& 3 & 50 & & \\
\hline
\end{tabular}

Box 1. Table legend

\begin{tabular}{|l|l|}
\hline Symbol & Explanation \\
\hline SR & Set out rate \\
\hline PR & Participation rate \\
\hline C\&P & Cans and plastics \\
\hline P & Paper \\
\hline$\varnothing$ & Average \\
\hline$\Sigma$ & Total \\
\hline
\end{tabular}

\section{Analysis of data}

For continuity, the results for garden waste are not included in this initial analysis. The key trends that can be extracted from the data are: 
i. Following the introduction of the new scheme the set out rate and participation rate increased in the trial area but experienced a drop in Phase 3

ii. Set out rates and participation rates were higher in the trial area than control area

iii. Some households not recycling prior to the trials began to participate

iv. Consistently more households participated in can and plastic recycling than to paper recycling

v. The number of households placing material out for every collection in the trial area increased

vi. Excess waste levels in the trial area reduced following the introduction of the new scheme but increased in Phase 3

vii. Excess waste levels in the trial area were lower than the control area

viii. Recycling rates in the trial area were consistently higher than the control area

\subsection{Increase in set out and participation rates (see Table 4).}

Prior to the implementation of the scheme, the trial area had on average a $6 \%$ higher set out rate than the control round. Moreover, participation was also higher $72 \%$ in the trial area compared to $64 \%$ in the control area.

The implementation of the new system caused an immediate increase in set out and participation. In Phase 2, the average set out in the trial area increased to 59\% whereas the level of set out in the control area remained similar to that in Phase 1. In turn, participation in the trial area increased to $84 \%$ whereas participation in the control area remained static at $64 \%$.

By Phase 3 set out and participation had reduced in the trial area to 50\% and $76 \%$ respectively whereas results in the control area remained consistent with those recorded in the previous Phases. As Phase 3 took place several months after implementation of the new scheme, these rates were considered likely to be stable.

\subsection{Uptake in recycling (see Table 5)}

In each Phase of monitoring, some households did not take part in recycling whilst other residents set material out in every collection. Prior to the new scheme $28 \%$ of households in the trial area failed to place any dry recyclables out for collection. The onset of the scheme led to the number of non-participants reducing to $16 \%$ in Phase 2 . However, by the final Phase of analysis the level of non-participation increased back to $24 \%$. The level on non-recyclers remained consistently higher in the control area during the three Phases at $36 \%$ in the control area. This observation is discussed further in Section 9.

A similar, but more successful, trend was noted in regards the level of dedicated recyclers i.e. those that placed material out in every collection. In Phase 1, 14\% of households in the trial area set materials out every week. The introduction of the scheme led to the level of dedicated recyclers almost doubling to $27 \%$ in Phase 2 but by Phase 3 , this had reduced slightly to $20 \%$. In comparison, these levels varied from $11 \%$ to $16 \%$ in the control area. 
Figure 4. The number of households failing to take part in recycling at least once during the 12 week period of monitoring

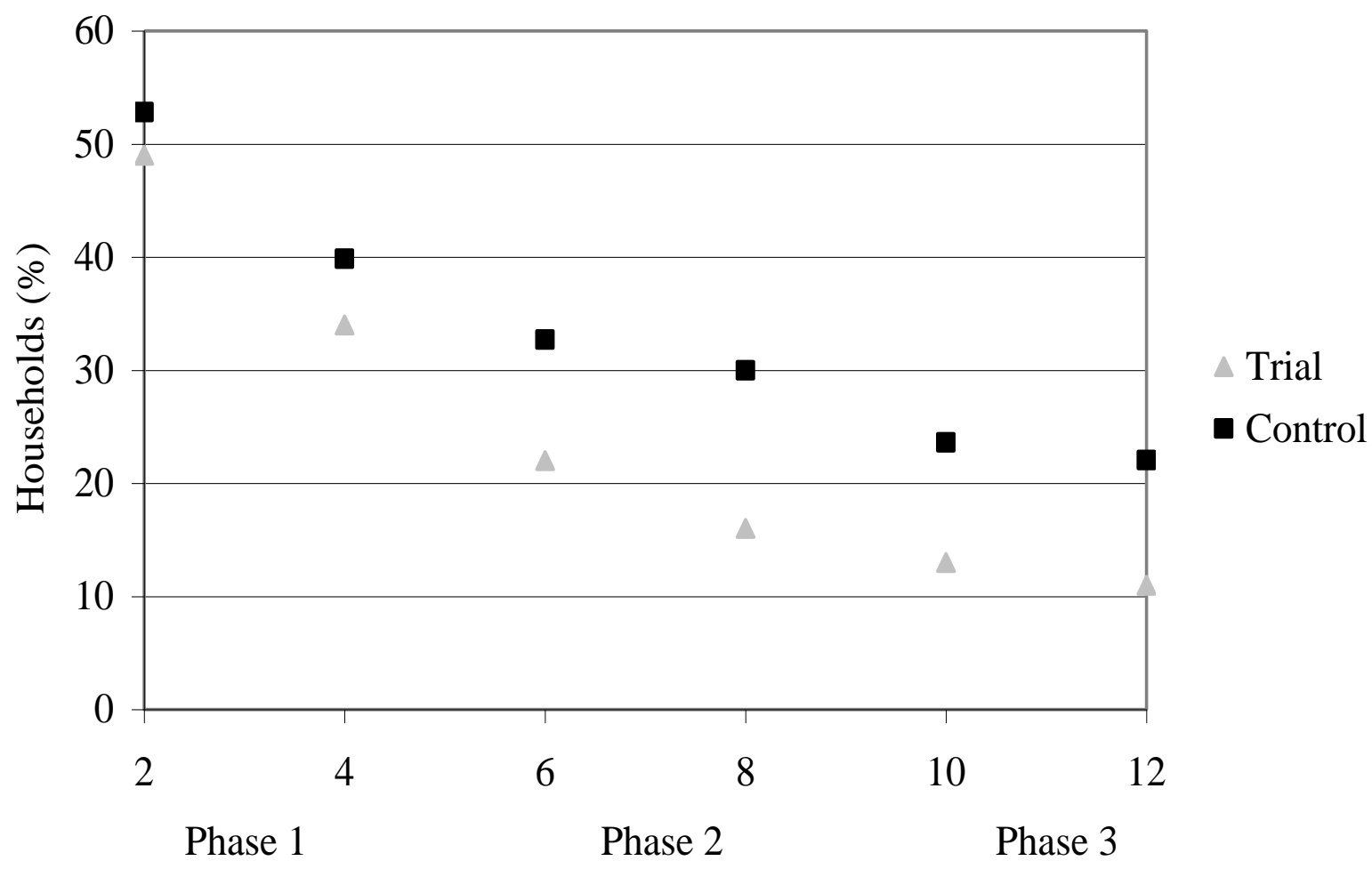

Analysis was also conducted to determine the changing levels of non-recyclers. As the project involved house-by-house monitoring not just for the standard 4 weeks needed to report a participation rate, but for a total of 12 weeks, carried out in groups of 4 weeks each in Phases 1,2 and 3, it was decided to use this as an opportunity to follow activities of non-recyclers (who never set out recyclates). Figure 4 shows nonparticipation rates - i.e. the numbers NOT participating. Prior to the new scheme being implemented $49 \%$ of households in the trial area and $53 \%$ of households in the control area had failed to place material out for collection at least once in the first fortnight, but the number dropped to $34 \%$ and $40 \%$ respectively by the end of the second fortnight in Phase 1. During Phase 2 several more households placed out recyclates, so that after four weeks of monitoring in that Phase the total number that had never set out was $17 \%$ in the trial and $30 \%$ in the control groups.

These numbers already show the weakness of the current standard of measuring participation (or non-participation in this case) rates over only four weeks; the control group had moved from $40 \%$ measured over four weeks to $30 \%$ as measured over eight weeks (although Phase 1 and Phase 2 monitoring was not strictly consecutive). By the end of monitoring a further four weeks in Phase 3, the control groups nonparticipation had fallen to $22 \%$ and seemed to be levelling out.

The trial group, however, shows the combined effect of changing numbers due to two effects. First, the effect described above where the non-participation rate 
decreases simply because it is measured over a longer period, until it stabilises. Secondly, an increase in participation due to actual increased recycling. Across the entire 12 weeks of monitoring their non-participation dropped from $49 \%$ to $11 \%$ a significantly bigger change to the control's drop from $53 \%$ to $22 \%$.

\subsection{Trends in material recycling}

Throughout the three Phases of monitoring participation levels in cans and plastic recycling was greater than that in paper recycling - this was the case in both the control and trial areas (see Figure 5). However, despite more households participating in can and plastic recycling weight analysis shows that participating households placed out an average of $0.9 \mathrm{~kg}$ of cans and plastic compared to $6 \mathrm{~kg}$ of newspaper and magazines.

Figure 5. Set out rates for dry recyclables over the 12 week period

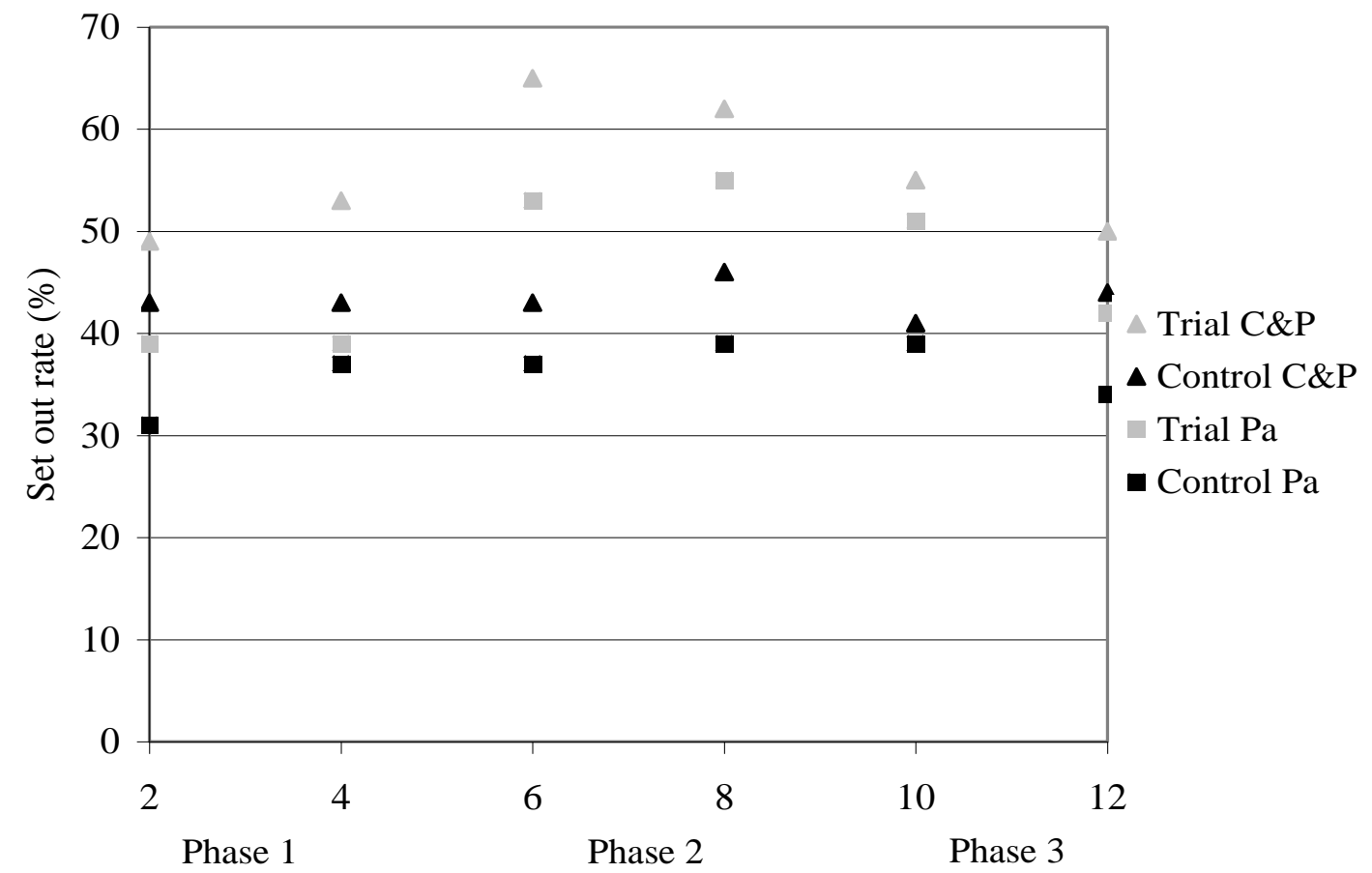

\subsection{Excess waste (see Table 6)}

In Phase $112 \%$ of households placed out excess waste for collection in the trial area, whereas some $7 \%$ placed out extra materials in the control area. Following the implementation of the scheme excess waste levels fell to $2 \%$ of households in the trial area compared to $11 \%$ in the control group. By Phase 3, it appeared that some households in the trial area were either struggling to cope with the scheme or reverting to their previous ways as levels of excess waste increased to $5 \%$. In comparison $8 \%$ of households in the control group placed out extra material. These results indicated the need to reconsider whether the trial scheme needed to provide more capacity for recyclates, or whether householders needed further education on recycling and how to manage their waste. 


\subsection{Increase in recycling rates (including garden waste)}

Weight data was collected from both the control and trial areas for the initial 16 weeks after the new scheme had been implemented. Whereas the control area recorded an average recycling rate of $12 \%$, the trial area attained $52 \%$. The highest recorded recycling rate in the trial area was $62 \%$ in the first fortnight period of collection whilst the lowest was $48 \%$ in the third fortnight period (see Figure 6).

\section{Figure 6. Recycling rates recorded over initial 16 weeks of collection}

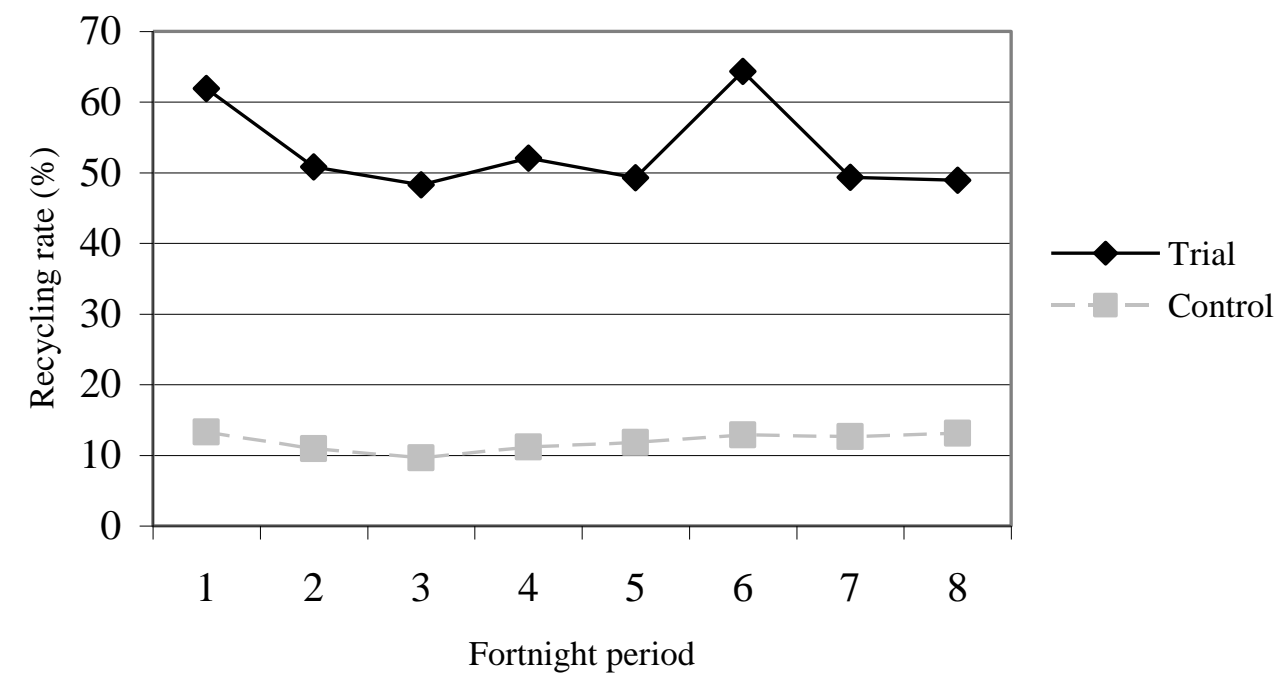

\subsection{Garden waste (see Table 7)}

Four hundred and seventy households were provided with a wheeled bin for garden waste and cardboard. In Phase 2, set out rates of $74 \%$ and $73 \%$ were recorded. By Phase 3 set out had reduced to 59\% and 50\% (see Table 7). This equates to an $86 \%$ participation rate for garden waste in Phase 2 with a drop off to $72 \%$ in Phase 3. When including garden waste in the overall participation figure for the area, participation increases to $92 \%$ in Phase 2 and $84 \%$ in Phase 3, an increase of $8 \%$ in both Phases. Garden waste was the most common material set out in Phase 2. By Phase 3 set out had reduced to a similar level to that of cans and plastic.

\section{Discussion}

The first and most important finding has been the apparent success of the trial in meeting the principle aim of increasing the recycling rate. Following the implementation of the new scheme in the trial area higher levels of set out, participation and recycling were recorded than that experienced in the previous scheme and also in the control area. For the initial 16 weeks of collection, an average 
recycling rate of $52 \%$ was recorded in the trial area compared with $12 \%$ in the control area. There are several potential contributing factors for these changes in trends.

The first factor was the careful planning of the scheme. The system was specifically designed for the requirements of Horsham District based on established, successful ideas in operation elsewhere. The system intended to maximise the potential of the waste stream by capturing materials such as garden waste and cardboard, which were not previously being recycled. The scheme was also not overly ambitious; it made use of the existing collection and sorting infrastructure and it only included materials for which there was a secure market.

The implementation of a fortnightly collection scheme meant that in order for households to manage their waste effectively they had to recycle. This change may have had several impacts. For example, previous non-recyclers may have started to make use of the recycling facilities on offer whilst existing recyclers may have started to place more materials out for collection. Purchasing actions of residents may also have changed so that they brought products with less packaging or items packaged in materials that could have be recycled in the scheme. They may also have started to compost waste at home or delivered further materials to recycling centres (bring banks).

A strong emphasis was placed on education. As household waste was no longer to be collected on a weekly cycle the reason and justification for this change had to be effectively communicated to residents. Care was taken to visit each household included on the new scheme so that the dynamics could be explained and residents could ask questions. Residents were also given information packs that fully explained the logistics of the scheme. In addition a dedicated phone line was set up and a series of road shows were held thereby making dialogue between the Council and residents as accessible as possible.

Auditors carefully monitored the scheme and compiled details on individual households. If households failed to comply with the scheme, Council officers visited to find out why and a resolution sought. A flexible and reasonable approach was taken, for example if households containing large families could prove that they were recycling but they still could not manage their waste effectively then they were supplied with a further bin.

The combination of careful planning, education and auditing led to the scheme achieving its aim. However, by the third Phase of monitoring conducted 3 months following the new scheme being implemented it appeared that some of the households started to revert to their previous habits. For example, participation began to reduce and levels of excess waste began to increase. This trend was expected, as when a recycling scheme starts the dynamics of the scheme are fresh in the residents mind and therefore they place material out for collection. But several months on they may participate less which is sometimes referred to as recycling decay. Coggins (1994) cited that reasons for drop off in participation include operational problems, household mobility, irregular updating or limited reinforcement of publicity materials. Therefore it is imperative for households to receive innovative and on going publicity, which reinforces the need for constant education and publicity. Despite this drop off, levels of participation recorded in the trial area were consistently higher than they were in the area prior to the commencement of the new scheme and they remained 
higher than levels in the control area. Moreover, it is interesting to note that despite a drop off in participation the recycling rate remained consistent. This perhaps supports the view that a high participation rate does not necessarily equate to a high recycling rate (Wang, 1997).

Results show that more households set out cans and plastic from recycling than newspaper. There maybe several reasons for this. Cans and plastic take up more space in the dustbin and therefore they are an obvious material to recycle. Moreover, most households will have cans and plastic in their waste stream through food packaging. Newspapers and magazines take up less space and some households may not purchase those items. Newspapers and magazines can be used elsewhere: they maybe passed on for others to read, magazines maybe sold to second hand shops, they might be used in rabbit hutches and alike or when decorating. Some households also store newspapers and take them to bring bank facilities, particularly as sometimes these are affiliated with charities.

The high recycling rate was somewhat surprising as data from the waste analysis suggests that the scheme would only be handling 35\% of the waste stream (13\% already being collected and $22 \%$ additional material). It is likely that residents that previously delivered garden waste to the Civic Amenity site were now making use of the kerbside scheme. Moreover, whilst the results of the scheme appear to suggest that it has been successful in increasing recycling rates it does not take into account the full actions of residents. For example residents that were struggling to manage their waste may deliver excess waste to Civic Amenity sites and place material in the bin of neighbours.

\section{Further work}

The results suggest that the new scheme was successful in increasing levels of participation in recycling whilst also raising the recycling rate. However, as indicated in Phase 3 of analysis levels of participation were beginning to reduce. Future monitoring should be undertaken to assess how levels in participation continue to change.

It is important to gain feedback from residents in regards to how they were managing to cope with the scheme and how the system could be improved. Future research will look into the opinions of residents, question how their recycling activity has changed and gain information on the role of incentives. Moreover the research suggests that garden waste that would have previously entered the Civic Amenity waste stream was being diverted to the garden waste kerbside collection. Further research will investigate the impact that kerbside collection of garden waste can have upon waste flows into Civic Amenity sites and also home composting.

\section{Conclusion}

Local authorities throughout the UK are revising their recycling strategies as they attempt to meet challenging legislative targets. An important part of this process is the implementation of kerbside recycling schemes. This paper has shown the process of 
one authority as it attempts to double it recycling rate from a base of $13 \%$. Through revising the existing kerbside service on offer and integrating elements of successful schemes operating elsewhere a new scheme was developed and trialled that obtained an increase in setout, participation, and recycling rates. Furthermore, previous nonrecyclers started to use the scheme. Reasons for these changes may include the careful planning of the scheme, the emphasis on education and the detailed auditing undertaken.

\section{Acknowledgements}

The authors acknowledge the residents of Horsham and Horsham District Council in assisting in the completion of this research.

\section{References}

Andress, C. 1990. Innovative funding for recycling programmes. Biocycle, August 1990: $50-53$.

Belton, B., Crowe, D., Matthews, R. and Scott, S. 1994. A survey of public attitudes to recycling in Glasgow (U.K.). Waste Management \& Research, 12: 351-367.

Bench, M. L., Woodard, R. and Harder, M. K. 2003. Household Waste Recycling Sites: waste material composition by weight with a view to facility optimisation. Chartered Institute of Wastes Management, 4, 2: 2-8.

CACI (2002) ACORN the complete consumer classification

Coggins, C. 1994. Who is the recycler ? Journal of Waste Management \& Resource Recovery., 1, 2: 69-75.

Daneshvary, D., Daneshvary, R. and Schwer, K. 1998. Solid-waste recycling behaviour and support for curbside textile recycling. Environment and Behaviour., 30, 2: $144-159$

DEFRA. 2002a. Municipal Waste Management Survey 2000/1. HMSO, London, UK.

DEFRA. 2002b. Foot and Mouth Disease 2001: Lessons to be Learned Inquiry Report. HMSO, London, UK.

DEFRA. 2003. Municipal Waste Management Survey 2001/2. HMSO, London, UK.

DETR. 1999. Monitoring and evaluating recycling, composting and recovery programmes. HMSO, London, UK.

DETR. 2000. Waste Strategy 2000. HMSO, London, UK.

DETR. 2001. Guidance on municipal waste strategies. HMSO, London, UK.

DoE. 1990. The Environmental Protection Act. HMSO, London, UK. 
DoE. 1994. The Technical Aspects of Controlled Waste Management-Research Report, The National Household Waste Analysis Project-Phase 2 Report on further Composition and Weight Data. Report no. CWM 086/94. HMSO, London, UK.

DoE. 1995. Making Waste Work. A strategy for sustainable waste management in England \& Wales. HMSO, London, UK.

De Young, R. 1990. Recycling as appropriate behaviour: a review of survey data from selected recycling education programs in Michigan. Resources, Conservation and Recycling., 3: 253-266.

Environment Agency. 2000. Strategic Waste Assessment: South East. Environment Agency, Bristol, UK.

Environment Council. 2000. The Stakeholders' Guide. Environment Council, London, UK.

European Environment Agency. 1999. Environment in the European Union at the turn of the century. European Environment Agency, Copenhagen, Denmark.

Everett, J. W. and Peirce. J. J. 1993. Curbside recycling in the USA: convenience and mandatory recycling. Waste Management \& Research., 11: 49-61.

Folz, D. H. and Hazlett, J. M. 1991. Public participation and recycling performance: explaining program success. Public Administration Review, 51: 526-532.

Great Britain. 1990a. This Common Inheritance.1990. HMSO, London, UK.

Great Britain. 1990b. The Environmental Protection Act. HMSO, London, UK.

Harder, G., Knox, L. 1992. Implementing variable trash collection rates. Biocycle, April 1992: 66-69.

Jenkins, R. R., Salvador, M. A., Palmer, K. and Podolsky, M. J. 2003. The determinants of household recycling: a material-specific analysis of recycling program features and unit pricing. Journal of Environmental Economics and Management, 45, 294-318.

Kendall, M. 2001. Setting an example. Wastes Management, January 2001: 18-19.

Letsrecycle.com. 2003. Paper prices www.letsrecycle.com/paper/paper02.htm

Miller Associates. 1999. Project Integra Research, attitudes and behaviour. Report 1: Main Findings. Southampton, UK.

National Statistics. 2003. Census 2001. www.statistics.gov.uk/census2001/

Network Recycling. 2001. Horsham District Council Household Waste Composition Study March 2001. Network Recycling, Bristol, UK. 
Noehammer, H. C., Byer, P. H. 1997. Effect of design variables on participation in residential curbside recycling programs. Waste Management \& Research, 15: 407427.

Parfitt, J. 2002. Analysis of household waste composition and factors driving waste increases. WRAP, Banbury, UK.

PaperChain. 2002. A guide to the quality requirements of recovered paper. PaperChain, Swindon, UK.

Platt, B., Docherty, C., Broughton, A. C., Morris, D. 1991. Beyond 40 percent: record setting recycling and composting Programs. Washington DC, USA.

Pocock, R. L. 1989. Multi-material recycling in Birmingham. MEL Wastes Research Report 89/06. Midland Environmental Ltd (MEL), Birmingham, UK.

Read, A. 1999. "A weekly doorstep recycling collection, I had no idea we could !" Overcoming the local barriers to participation. Resources, Conservation and Recycling., 26: 217-249

Redfearn. A., Docherty J. C. and Roberts R. D. 2000, Assessment of health effects associated with landfills. IWM Scientific \& Technical Review, April 2000: 14-28

Herridge, B. 2001. Public Education and Kerbside Recycling in the UK. University of Kingston, London, May 2001.

Salvation Army Trading Company Limited. 2002. www.tecweb.com/sa/

Strategy Unit. 2002. Waste Not, Want Not - A strategy for tackling the waste problem in England. Strategy Unit, London, UK.

Wang, F. S., Richardson, A. J. and Roddick, F. A. 1997. Relationships between setout rate, participation rate and set-out quantity in recycling programs. Resources, Conservation and Recycling, 20: 1-17.

Waste Watch. 1999. Diverting Messages. Waste Watch, London, UK.

WERG. 2002. Monitoring of the Paperchasers Recycling Scheme, A report by WERG on behalf of Brighton \& Hove City Council. WERG, Brighton, UK.

WERG. 2001. Monitoring of CHEERS Recycling Programme, A report for Crawley Borough Council. WERG, Brighton, UK.

Williams I. D., and Kelly. J., 2003. Green waste collection and the public's recycling behaviour in the Borough of Wyre, England. Resources, Conservation and Recycling., 38, 2: 139-159. 
Woodard, R., Bench, M., Greenfield, D. W. J. and Harder, M. K. 2002. Achieving Recycling Targets in the UK - Practical examples from East and West Sussex. ISWA World Congress, Istanbul, Turkey.

Woodard, R., Harder M. K., Bench. M. and Philip, M. 2001. Evaluating the performance of a fortnightly collection of household waste separated into compostables, recyclates and refuse in the south of England. Resources, Conservation and Recycling., 31: 265-284.

WRAP. 2002. Kerbside collection of glass - A brief study into the coverage and the effectiveness of kerbside collection in the UK. 